\title{
Supercritical Carbon Dioxide Turbo-Expander and Heat Exchangers
}

\begin{tabular}{|c|c|c|}
\hline $\begin{array}{l}\text { SOUTHWEST } \\
\text { INSTITUTE }\end{array}$ & RESEARCH & $\frac{S}{\mathbf{R}}$ \\
\hline PROGRAM: & SunShot CSP R\&D 2012 & \\
\hline TOPIC: & Advanced Power Cycles & \\
\hline LOCATION: & San Antonio, Texas & \\
\hline $\begin{array}{l}\text { AWARD } \\
\text { AMOUNT: }\end{array}$ & Up to $\$ 6.8$ million & \\
\hline PROJECT TERM: & 2012-2015 & \\
\hline
\end{tabular}

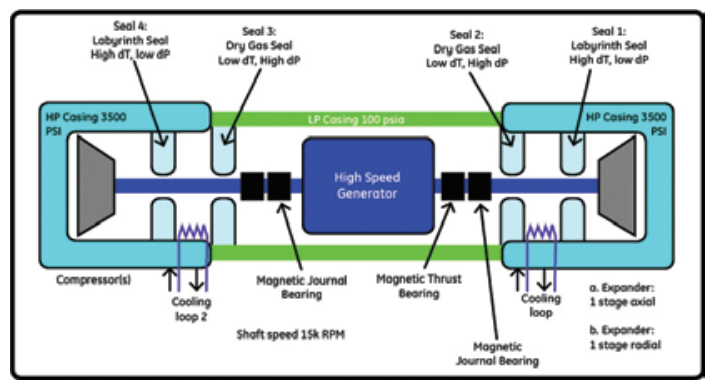

Conceptual layout of an integrated, high-efficiency supercritical $\mathrm{CO}_{2}$ hot gas turboexpander that is optimized for the highly transient solar power plant duty cycle profile. Illustration from Southwest Research Institute

\section{CONTACTS}

Project Leader:

Dr. Klaus Brun

klaus.brun@swri.org
Partnering Organizations:

- General Electric Global Research Center

- Thar Energy

- Bechtel Marine

\section{MOTIVATION}

Use of supercritical carbon dioxide $\left(\mathrm{s}-\mathrm{CO}_{2}\right)$ in a closed-loop recompression Brayton cycle offers higher cycle efficiency when compared with supercritical or superheated steam cycles at temperatures relevant for concentrating solar power (CSP) applications. Supercritical carbon dioxide is particularly well-suited as a working fluid for use in power towers. A single-phase process using s- $\mathrm{CO}_{2}$ as both heat transfer and thermal cycle fluid would simplify the powerblock machinery and is compatible with sensible-heat thermal energy storage.

\section{PROJECT DESCRIPTION}

The research team is working to develop a megawatt-scale s- $\mathrm{CO}_{2}$ hot-gas turbo-expander optimized for the highly transient solar power plant profile. The proposed CSP power cycle uses s- $\mathrm{CO}_{2}$ as both the heat transfer fluid in the solar receiver and the working fluid in the power cycle. The team is also working to optimize novel printed circuit heat exchangers for s- $\mathrm{CO}_{2}$ applications to drastically reduce their manufacturing costs.

\section{IMPACT}

The lower thermal mass and increased power density of the $\mathrm{s}-\mathrm{CO}_{2}$ power cycle enables the development of compact, high-efficiency power blocks that are compatible with sensible-heat thermal energy storage. Because they can also respond quickly to transient environmental changes and frequent start-up/shut-down operations, these smaller, integrated power blocks provide an ideal solution for modular tower-mounted CSP plants in the 5-10 MW range.

For more information, visit the project page at: www.solar.energy.gov/sunshot/csp_sunshotrnd_swri_exchangers.html. 